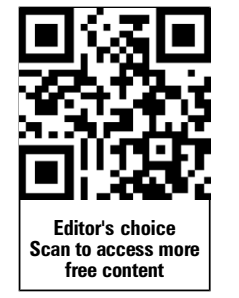

${ }^{1}$ Antidoping Agency of Serbia, Belgrade, Serbia

${ }^{2}$ FIBA Europe Medical Council, Munich, Germany

${ }^{3}$ College of Human and Health

Sciences, Swansea University,

Swansea, UK

${ }^{4}$ Ministry of Youth and Sport,

Belgrade, Serbia

WWADA Foundation Board

Belgrade, Serbia

\section{Correspondence to}

Professor Michael McNamee,

College of Human and Health

Sciences, Swansea University,

Swansea SA2 8PP, UK;

m.j.mcnamee@swansea.ac.uk

Received 1 October 2012

Revised 11 December 2012

Accepted 17 December 2012

Published Online First

15 January 2013

\title{
Sports physicians, ethics and antidoping governance: between assistance and negligence
}

\author{
Nenad Dikic, ${ }^{1,2}$ Michael McNamee, ${ }^{3}$ Heinz Günter, ${ }^{2}$ Snezana Samardzic Markovic, ${ }^{4,5}$ \\ Bojan Vajgic ${ }^{1}$
}

\section{ABSTRACT}

Recent positive doping cases and a series of mistakes of medical doctors of the International Federation of Basketball have reopened the debate about the role of medical doctor in elite sport. This study shows that some sports physicians involved in recent positive doping cases are insufficiently aware of the nuances of doping regulations and, most importantly, of the list of prohibited substances. Moreover, several team doctors are shown to have exercised poor judgement in relation to these matters with the consequence that athletes are punished for doping offences on the basis of doctors' negligence. In such circumstances, athletes' rights are jeopardised by a failure of the duty of care that (sports) physicians owe their athlete patients. We argue that, with respect to the World Anti Doping Code, antidoping governance fails to define, with sufficient clarity, the role of medical doctors. There is a need for a new approach emphasising urgent educational and training of medical doctors in this domain, which should be considered prior to the revision of the next World Anti Doping Code in 2013 in order to better regulate doctor's conduct especially in relation to professional errors, whether negligent or intentional.

\section{INTRODUCTION AND CONTEXTUALISATION}

Notwithstanding collusion by physicians in systematic doping, ${ }^{1-4}$ the most important case of doctor fault in relation to doping offences was probably that of Andrea Raducan's case in the Olympic Games in Sydney, when she was stripped of her Gold medal after testing positive for pseudoephedrine (see S6. Stimulants), which was contained in nurofen, a common over-the-counter antiinflammatory medicine. ${ }^{4} \mathrm{~A}$ few words regarding her history and status are necessary to understand the sporting tragedy that evolved in relation to her doping offence.

Andrea Raducan, one of the greatest gymnasts of her generation, was born in 1983. She started to train at the age of 4 , while by the time, she was 14 , she represented the Senior Romanian team, and made her debut at the Sydney Olympic Games when she was aged only 16. In 1999, she won gold as an individual in the Floor Exercises and gold in the Team Event at the World Gymnastics Championships, and silver on the Beam. At the Sydney Olympics, she won gold in the gymnastics (artistic) women's team finals and won an individual silver medal on the vault.

From 1996, she was under the control and direction of, among others, Dr Ioachim Oana, the Romanian gymnastics team doctor. ${ }^{5}$ During the competition at the Olympic Games, she reported a headache, a running nose and a feeling of congestion to Dr Oana, who prescribed and issued her a nurofen, an anti-inflammatory drug. He gave her a second nurofen tablet during the warm-up women's individual all-around event. She won gold in the gymnastics (artistic) women's individual allaround event. Subsequently, however, she failed a doping control, testing positive for pseudoephedrine and was stripped of her gold medal by the International Olympic Committee (IOC). ${ }^{6}$

Raducan said that she bore no responsibility for the antidoping rule violation (ADRV), since the nurofen pills were given to her by her team doctor with whom she had a relationship of trust, and that the pills had not been performance-enhancing. She competed weighing only $37 \mathrm{~kg}$, a statistic that is important when considering the effects regarding the concentration of the drug. Nevertheless, because of the strict liability condition, ${ }^{7}$ the IOC antidoping panel and later the Court of Arbitration for Sport (CAS) were implacable. The World Anti Doping Code (WADC) makes it clear that there is no need to prove the intent to cheat via the use of performance-enhancing substances, but merely the presence of prohibited substances in the athlete's body is enough. Athletes have a duty to avoid the presence of such substances within their person. This is known as 'strict liability'.

The case generated a significant amount of media attention about the role of team doctor. The team doctor who administered the nurofen was banned for two Olympic cycles. It is noteworthy, however, that the then WADC and antidoping regulations did not precisely define the role of medical doctor. The situation persists today, though greater clarity exists of the role of physicians in relation to the therapeutic use exemption certificate ${ }^{8}$ for athletes who have a clinical need for substances that are simultaneously on the prohibited list (PL) because of their (potential) ergogenic or (potential) harmful effects.

\section{MATERIAL AND METHODS}

We analyse four result management decisions done by the Antidoping Agency of Serbia and the International Basketball Federation (FIBA) in 2010 which involved team doctors: one regarding an international Serbian handball player ${ }^{9}$ and three doping cases of FIBA.

\section{RESULTS}

An international Serbian handball player was tested positive in June 2010 for the substance of hydrochlorothiazide during in-competition testing at the French national championship. According to his 
medical history, he had been treated by ACE inhibitors, calcium antagonists and diuretics since 2008 because of hypertension. The therapy is prescribed by a cardiologist from Belgrade, confirmed by the team doctor of the Handball Club Partizan, Belgrade, Serbia, and then by the team doctor of the Dunkerque Handball Club: HB Grand Littoral, Dunkerque, France, and finally by the team doctor of the Handball Club Kolubara, Lazarevac, Serbia. What is important here is that the player has been seen by various medical doctors. What is even more important is the player has informed French doping control officer during doping control about his use of the diuretic, which is on World Anti-Doping Agency's (WADA) PL (S5. diuretics and other masking agents). Yet, there are hypertension treatments available that are not on the PL, a point that the physician ought to have been aware of. Nevertheless, the doping control officer did not put it on the list of medications the one the athlete had taken during the week prior to the control. What is clear here, that as an adult, the athlete themselves bears some responsibility (not just liability) to present themselves at competition in such a way that does not fall foul of the WADC's regulations. Finally, the player was given a 10-month ban, while financial penalties were subjected to the two medical doctors by the civil courts in Serbia. ${ }^{8}$

Our second case can be seen to fall somewhere between the cases of the handball player and Raducan in terms of the role played by sports physicians. A young Russian basketball player, committed an ADRV by the use of nandrolone (S1. anabolic agents). He had been treated by a Russian team doctor following two fractures (the instep bone of the right hand, and left fibula). The physician ought to have chosen another medication with similar effects that was not on the PL. In spite of this offence, the player argued that he had no idea that the injections contained substances on the PL, that he had not committed previously any ADRV, and that he was unable to properly give consent as a minor. Nevertheless, under the auspices of strict liability, he received a 1-year punishment while the team doctor received a lifetime ban from FIBA. ${ }^{10}$ What is further worthy of note here is the discretion of the FIBA panel. Had the doping offence been detected by, for example, a more lenient antidoping panel, it is not immediately clear that a 1-year sanction would be handed down, given the (fairly clearly) accidental nature of the ADRV from the athlete's perspective.

The third case is that of French basketball player, who underwent an in-competition doping test in July 2010 in Zadar, Croatia, on the occasion of the France-Spain semifinal of the FIBA Europe U-20 Men's Championship. Upon being found to have committed a doping offence, he was handed a 1-month ban while there was no punishment for the team doctor concerned. The player had filed a declaration of use for ventolin (salbutamol) with the French National Anti Doping Organization (Agence Française de Lutte Contre le Dopage) (NADO (AFLD)). During the game, however, he suffered an asthma attack and was urgently treated by the team doctor (whom the athlete did not choose, but may reasonably have assumed, was familiar with the $\mathrm{PL}$ ), with an inhaler called Bricanyl (containing terbutaline, which is on the PL: S3. $\beta-2$ agonists). The team doctor had treated him in the mistaken belief that the declaration of use covered all $\beta$-2-agonists. The physician thus mixed different $\beta$-agonists, and though sabutamol and terbutalin are from the same group, he did not use the drug that had been registered on the therapeutic use-exemption (TUE) certificate. This oversight caused the ADRV to arise in the doping control. Unsurprisingly, it was argued that the player bears neither fault nor negligence for this ADRV, since this was clearly a mistake by the team doctor and that he had committed no previous ADRV. Again, from the athlete's perspective, this is one of the difficulties of the WADC regarding strict liability. ${ }^{9}$

The fourth and final case to be considered is that of a Spanish basketball player, who underwent an in-competition doping test on July 2010 in Toulouse, France, after the end of the USA versus Spain quarter-final of the FIBA U17 Women's World Championship. The analysis showed the presence of the prohibited substance chlorthalidone (S5. diuretics and other masking agents) in the player's sample. Problems began for the athlete in spring 2010 when, it is alleged, she gained weight as a result of stressful school exams. The Spanish national team coach asked the player's parents to monitor her weight and initiate a diet with the purpose of rapid weight loss. After having unsuccessfully tried to lose weight, she was contacted by the team doctor of the Spanish Basketball Federation responsible for the U-17 Women's team who recommended a supplement named 'Obesity A'. It should be noted that a TUE would not normally be granted for this product. Upon joining the national team's training camp in early July, however, the team doctor asked her to discontinue taking the pills. Despite this, she continued using the drug, so it is clear that her doping offence could at best be considered careless and, at worst, a case of intentional doping. Upon committing the ADRV, she received a ban of 9 months.

\section{DISCUSSION}

Each of these cases highlights different aspects of the general considerations of fiduciary relationship between the athlete and sports physician. ${ }^{11}$ The duties of care of sports physicians that are not affected here range from negligence to lack of followthrough in treatment cessation. None of the cases can be called 'physician-assisted doping' in a strong sense, such as were witnessed in the Tour de France during the 1990s. In general, medical doctors are defined as 'athlete-support personnel' in the 2009 Code. $^{12}$ It is said that 'athlete-support personnel' (often called the 'athlete entourage') comprises any coach, trainer, manager, agent, team staff, official, medical, paramedical personnel, parent or any other Person working with, treating or assisting an athlete participating in or preparing for sports competition.

The code also defines, in very general terms, the role and competencies of medical doctors in relation to doping in article 21.2:

- To be knowledgeable of and comply with all antidoping policies and rules adopted pursuant to the code and which are applicable to them or the athletes whom they support (article 21.2.1).

- To cooperate with the Athlete Testing programme. (article 21.2.2).

- To use their influence on athlete values and behaviour to foster antidoping attitudes. (article 21.2.3).

Finally, the code defines punishment of medical doctors in article 10.3.2. For violations of articles 2.7 (trafficking or attempted trafficking) or 2.8 (administration or attempted administration of prohibited substance or prohibited method), the period of ineligibility imposed shall be a minimum of 4 years up to lifetime ineligibility. An ADRV involving a minor is considered especially serious because of the failure of a heightened fiduciary obligation, ${ }^{10}$ and, if committed by athletesupport personnel for ADRVs other than specified substances referenced in article 4.2.2, shall result in lifetime ineligibility for athlete-support personnel.

The central aim of the WADA code with respect to athletesupport personnel is that those who are involved in 
'physician-assisted doping' in a strong sense, or assisting athletes in masking doping practices should be subject to sanctions that are more severe than the athletes who test positive. The athlete is always responsible for any prohibited substance in his body (article 2.1) under strict liability, but the period of ineligibility shall be reduced or even eliminated if player can establish that they bear no fault or negligence. In line with strict liability, antidoping panels typically argue that players did not ensure that no prohibited substances enter their body, and because of this, they cannot shift their responsibility under the rules to support personnel. Nevertheless, antidoping tribunals may hold that a player's negligence is not insignificant and that it is, therefore, appropriate to impose variable sanctions on them.

Case 1, that of the handball player, is an interesting and complex one. Clearly, his case passes through the hands of several physicians; some local, some international physicians, one non-sport physician, several club doctors and an event physician. The potential for confusion, lack of clarity, oversight or even neglect, is obvious. Nevertheless, the consulting physician is professionally obliged to work in the athletes' best interests. This entails, in the case of team doctors and event physicians, that they are sufficiently aware of their obligations arising from the WADC. There are a number of issues of poor governance that can be highlighted here in the form of questions. Precisely, who ought to be accountable for the neglect of the TUE certificate being gained? To what extent are the records of the athlete patient shared among treating physicians at international events? How ought data sharing be better effected? Who has the ultimate responsibility for athletes' use of proscribed substances at any given time?

In the three FIBA cases (cases 2-4) presented above, the Russian athlete (case 2) received a 1-year sanction because of anabolic steroids use, while the other two players (cases 3 and 4) were punished between 1 and 9 months, reflecting offences of lesser performance-enhancing seriousness and the apparent therapeutic context of the offence. Moreover, concerning the athlete entourage, only the Russian doctor (in case 1) was significantly punished. Despite the fact that the Russian doctor used nandrolone inappropriately, this difference demonstrates the need for an urgent policy debate concerning governance. It is far from clear that case 1 and 2 merit such substantially different treatment for the doctors concerned. Specifically, it raises questions regarding the efficacy of the WADC in relation to the responsibility of doctors in sport. The need is not new. ${ }^{13-15}$ It is not clear precisely how well-founded are fears that the revised WADC may include physicians in the group of persons who can fulfil the elements of a doping offence. ${ }^{16}$

Athletes are expected to bear most of the responsibility for taking medical drugs and supplements that are potentially performance enhancing, harmful, and/or contrary to the spirit of sport, yet sport physicians are responsible to athletes for questions regarding antidoping and medical care. If athletes cannot rely on the trustworthiness of physicians, particularly in relation to their competence regarding anti-doping regulations, then it would seem that their right to proper healthcare in the contexts of elite sports medicine is jeopardised. On the other hand, one can ask whether the supply of qualified sports physicians may dry up if colleagues are repeatedly found guilty of ADRVs.

From another aspect, medical doctors are often seen to be held responsible by sport administrators, athletes and the general public. The main accusations made are, first, that some are engaged in 'physician-assisted doping', and second, that they supply athletes with doping agents, through carelessness. ${ }^{1}{ }^{17}$ In the study by Laure $e t a l^{2}$ up to $61 \%$ of adult amateur athletes stated that they obtained anabolic steroids and other banned drugs from a doctor. It has been shown that general practitioners' (GPs) knowledge of prohibited substances in sport is poor. Greenway and Greenway ${ }^{18}$ in their survey has showed that only $53 \%$ of GPs were aware of banned drugs, and that $12 \%$ believed that medical practitioners were allowed to prescribe anabolic steroids for non-medical reasons. A Dutch study of 1000 GPs was even clearer: $85 \%$ of the respondents admitted that they were not familiar with banned drugs or their side effects. ${ }^{1}$ If, as in this study, doctors are the most common source of information for the athletes (61\%) then the situation become more problematic. ${ }^{3}$

WADA has argued for the necessity to systematically work with doctors about (1) use of performance-enhancing drugs (including pain killers, doping agents etc), recreational drugs and other products (extra proteins, vitamins), and legal substances such as tobacco or alcohol; (2) health risks (physical and psychological) as effect of doping agents and a way to identify them during a clinical and/or biological examination. ${ }^{19} 20$ The same issues are noted by Striegel and Geoffrey elsewhere. ${ }^{21} 22$ It is problematic (not least for athletes) that medical doctors do not regularly improve their knowledge and attitudes to doping issues. This seriously brings into question the quality of training of medical doctors involved in sport on the subject of doping. Moreover, the issue raises the familiar problem of the specialism itself and the differing international standards for who may legitimately be called a sports physician and the level of training required for such. It is clear that holding GPs and specialist sports physicians, accountable to the same degree, would offend natural justice. Nevertheless, it seems that from the cases discussed above, that are not atypical, ${ }^{17}$ medical doctors are not familiar with the PL and/or that they do not use it in practice. As a result, doctors are not always aware of what it is that they are being asked, or they simply do not realise that certain prescribed medications can be misused for doping purposes. This situation is likely to be compounded in situations where there is an event physician covering a variety of athletes and teams of whom the physician is unlikely to have a full medical history. Whether employing organisations should take some responsibility for checking up-to-date knowledge of antidoping protocols of the sports physicians whom they engage is a point worthy of serious consideration.

What is also clear is that WADA are somewhat impotent in the process of disciplining members of the athletic entourage. National and International Sports Federations can apply sanctions (though, as we have noted above, this is fair from standardised) to prevent doctors, physiotherapists and other healthcare professionals from working with individuals or teams. What is more likely to be effective is interagency collaboration between WADA, Institute of National Anti-Doping Organisations (or international antidoping organisations such as Europe's CAHAMA group) in order to bring pressure to set international antidoping education guidelines. They ought also, however, to bear on individual healthcare professionals via their licensing associations. For the most egregious of infractions, the temporary revoking of licenses might be considered. This would not be without precedent. ${ }^{17}$ Indeed, the physician involved in that case, back in 1989 in Canada in the wake of the Ben Johnson incident, was held not to be fit to practice and had his licence revoked.

\section{CONCLUSION}

Our study of these four cases of doping offences showed that (at least some) team doctors are not sufficiently aware of the 
problem of doping in sport. This ignorance or neglect has led to serious consequences in the lives of dedicated elite athletes and, in one case at least, for the physician. Sports medicine as a specialism is still in the early years of professionalisation, and standards vary widely around the globe. Given the heterogeneous demands upon GPs it is unreasonable to expect them to have any detailed awareness of the PL. Elite athletes do not comprise the vast majority of patient cases. Here, athletes must be empowered by antidoping education from NADOs and International Federations, to have the awareness that they should inform the physician of their fairly unique occupational needs and related governance. This is one reason why antidoping jurisprudence ${ }^{23}$ acknowledges a lesser responsibility if the athlete finds themselves in the care of a physician they have not chosen, such as an event physician, or a national team doctor with whom they do not have an ongoing professional relationship. After that, one can reasonably expect the physician to make themselves aware of the athlete's needs and act accordingly. Other researches show that these cases are not isolated incidents but symptomatic of a wider professional issue. ${ }^{24}$ Clearly, international federations have a duty to guide their athletes towards specialist sports physicians where this is possible, and where a higher duty of care can be expected. Yet, many sports physicians simply do not know doping regulations or the PL in sufficient detail. Many of them have committed errors or have failed in their duty of care to athletes while it is the athletes that are punished. It is clear that athletes' rights are jeopardised in at least some of these circumstances and this demands a new approach and prompt education and adequate training of medical doctors in this domain. From the perspective of doping Governance, the WADC, the role of medical doctors must be defined with greater clarity, and antidoping education taken more seriously. Thus, in the period of WADC revision processes before the World Anti-doping Conference of 2013, it is necessary to better define the role of medical doctor in sport and more precisely to regulate punishment of physician errors in a way that is both systematic and fair across international boundaries and sports federations.

\section{What are the new findings?}

- Highlights non-harmonised sanctioning of physicians in antidoping rule violations.

- Argues that World Anti Doping Agenciess code revision process must consider issuing guidance concerning sanctions for physicians in relation to antidoping rule violations.

- Suggests that sanctions for general practitioners should not be the same as those for specialist sport physicians.

\section{How might it impact on clinical practice in the near} future?

- Better antidoping educational programmes for all physicians who are engaged in sport.

- Clearer and more specific agreements regarding antidoping prior to engaging physicians in sport-related practice.
Contributors ND, as a Director of Anti-doping Agency of Belgrade and Vice President of FIBA Europe Medical Council, has collected and analysed the data, and cowrote the paper. HG, as Chair of FIBA Europe Medical Council and Chair of FIBA Medical Committee, has provided FIBA data, analysed and interpreted data. SSM, as a Member of WADA Foundation Board and Minister of Youth and Sport, gave legal and other interpretation of the data. BV, lawyer and legal adviser of Antidoping Agency of Serbia, has led the result management process of Serbian handball player and provide necessary comments of result management of FIBA basketball players. MM, supplied supporting literature and review, interpreted data and cowrote the paper.

Funding MM's contribution written with the support of the European Commission FP7 Science in Society funded project, Ethics in public policy making: the case of human enhancement (EPOCH), grant number SIS-CT-2010-266660 http:/l epochproject.com

\section{Competing interests None.}

Provenance and peer review Not commissioned; externally peer reviewed.

\section{REFERENCES}

1 Laure $\mathrm{P}$, Binsinger $\mathrm{C}$, Lecerf $\mathrm{T}$. General practitioners and doping in sport: attitudes and experience. Br J Sports Med 2003;37:335-8.

2 Laure P. Doping in sports: doctors are providing drugs. Br J Sports Med 1997:3:258-9.

3 Somerville SJ, Lewis M. Accidental breaches of the doping regulations in sport: is there a need to improve the education of sports people? Br J Sports Med 2005;39:512-16

4 Kuipers H, Ruijsch van Dugteren G. The Prohibited List and Cheating in Sport. Int J Sports Med 2006;27:80-2.

5 Arbitration CAS ad hoc Division (0.G. Sydney) 00/011 Andrea Raducan/International Olympic Committee (IOC), award of 28 September 2000. http://arbitrationlaw.com/ files/free_pdfs/CAS\%2000-011\%20AR\%20v\%20I0C\%20Award.pdf (accessed 7 Jan 2013).

6 http://theelitegymnast.wordpress.com/category/andreea-raducan-rom/ (accessed 5 Dec 2010).

7 McNamee MJ, Tarasti L. Ethical and juridical peculiarities of anti-doping legislation. J Med Ethics 2010;36:165-9.

8 Hildebrand RL. The World Anti Doping Program and the Primary Care Physician. Ped Clin N Am 2007;54:701-11.

9 Case of Milos Milinic. Antidoping agency of Serbia Archive. http://www.adas.org.rs/ eng/services/doping-control-for-athletes.php - (accessed 04 Dec 2011).

10 http://www.fiba.com/pages/eng/fc/expe/medi/antiDopi/p/openNodelDs/1230/ selNodelD/1230/dopiCase.html (accessed 5 Dec 2010).

11 Holm S, McNamee MJ, Pigozzi F. Ethical practice and sports physician protection: a proposal. Br J Sports Med 2011;45:1170-3.

12 http://www.wada-ama.org/Documents/World_Anti-Doping_Program/ WADP-The-Code/WADA_Anti-Doping_CODE_2009_EN.pdf (accessed 21 Dec 2010).

13 McNamee MJ, Phillilps N. Confidentiality, disclosure and doping in sports medicine. Br J Sports Med 2011;45:174-7.

14 Dawson R, McNamee MJ. Doctors duties and doping dilemmas. In: Møller V, McNamee MJ, Dimeo P, eds. Elite sport, doping and public health. Odense: University of Southern Denmark Press, 2009:179-90.

15 Waddington I. Doping in sport: some issues for medical practitioners. In: Hoberman J, Møller V, eds. Doping and public policy. Odense: University Press of Southern Denmark, 2004:31-44.

16 Streigel H, Rössner D, Simon P, et al. The world antidoping code 2003consequences for physicians associated with Elite Athletes. Int I Sports Med 2005;26:238-43.

17 Pipe A, Best T. Editorial drugs, sport and medical practice. Clin sp med 2001;12:201-2.

18 Greenway P, Greenway M. General practitioner knowledge of prohibited substances in sport. Br J Sports Med 1997:31:129-31.

19 http://www.wada-ama.org/en/Education-Awareness/Social-Science/ Researchers-Directory/Last-name-A-E/_-(accessed 05Dec 2010)

20 http://www.wada-ama.org/en/Education-Awareness/Tools/For-Sport-Physicians/ (accessed 24 Nov 2011).

21 Striegel H, Simon P, Wurster C, et al. The Use of Nutritional Supplements Among Master Athletes. Int J Sports Med 2006;27:236-41.

22 Geoffrey MV, Peter DB, Hugh GS. Doctor on the sidelines. MJA 2006:184:244-8.

23 Niggli O, Sieveking J. Selected case law rendered under the World Anti Doping Code http://www.wada-ama.org/Documents/World_Anti-Doping_Program/ WADP-Legal_Library/Legal_Articles_On_The_Code/Jusletter_eng.pdf (accessed 29 Nov 2012).

24 Hoberman J. Sport physicians and the doping crisis in elite sport. Clin Sp Med 2002:12:203-8. 